\title{
Sex differences and HIV status of tuberculosis in adults at a rural hospital in southern Ethiopia: an 18-year retrospective cross-sectional study
}

\author{
José M Ramos ${ }^{1,2}$, Belén Comeche ${ }^{1,3}$, Abraham Tesfamariam ${ }^{1}$, Francisco Reyes ${ }^{1}$, Gebre Tiziano ${ }^{1}$, \\ Seble Balcha ${ }^{1}$, Tamasghen Edada ${ }^{1}$, Dejene Biru ${ }^{1}$, Mario Pérez-Butragueño ${ }^{1,4}$, Miguel Górgolas ${ }^{1,5}$
}

1. Department of Medicine and Pediatrics, Gambo Rural General Hospital, Ethiopia.

2. Department of Internal Medicine. Alicante General University Hospital, ISABIAL, and Miguel Hernández University of Elche, Alicante, Spain

3. National Referral Unit for Tropical Disease, Infectious Diseases Department, Ramón y Cajal University Hospital, IRICYS, Madrid, Spain

4.Departament of Pedaitrics, Infanta Leonor University Hospital, Madrid, Spain

5. Division of Infectious Diseases, Fundación Jiménez Diaz University Hospital, and Autonomic University of Madrid, Madrid, Spain

\begin{abstract}
Background. The aim of the study was to compare the epidemiology, clinical characteristics and treatment outcome of tuberculosis (TB), including HIV status, in women and men in southern rural Ethiopia.

Methods. We conducted a register-based retrospective cohort study covering the period from September 1998 to August 2015.

Results. We included records of 2252 registered TB patients: 1080 (48\%) women and $1172(52 \%)$ men. Median age was similar for women and men: 27.5 years and 25.0 years, respectively. Median weight in women was $43.0 \mathrm{~kg}$ (interquartile range IQR: $38.0,49.0)$, significantly lower than in men $(50.0 \mathrm{~kg}$, IQR 44.0, 55.0; $\mathrm{p}=0.01)$. Extrapulmonary TB was significantly more common in women than in men $(34.1 \%$ versus $28.7 \%$; $=0.006)$. Treatment outcomes were similar in both sexes: in $70.3 \%$ of women and $68.9 \%$ of men, TB mortality was slightly lower in women than men $(4.7 \% \mathrm{vs} .6 .5 \%$; $\mathrm{p}=0.08)$. In patients with TB, female sex was independently associated with low weight (adjusted aOR: 0.91; 95\% CI 0.90, 0.92), less mortality (aOR: $0.54 ; 95 \%$ CI 0.36, 0.81), and lymph node TB (aOR: 1.57 ; 95\% CI 1.13, 2.19)

Conclusion. Lymph node TB was more common in women. Treatment outcomes were similar in both sexes, but women had a lower mortality rate.

Keywords: Tuberculosis; tuberculosis, lymph node; female; women; sex; gender; Ethiopia.

DOI: https://doi.org/10.4314/ahs.v20i2.8

Cite as: Ramos JM, Comeche B, Tesfamariam A, Reyes F, Tiziano G, Balcha S, Edada T, Biru D, Pérez-Butragueño M, Górgolas M. Sex differences and HIV status of tuberculosis in adults at a rural hospital in southern Ethiopia: an 18-year retrospective cross-sectional study. Afri Health Sci. 2020; 20(2): 605-614. bttps:// doi.org/10.4314/abs.v20i2.8
\end{abstract}

\section{Introduction}

Tuberculosis (TB) is a major health problem worldwide, and men are significantly more at risk than women. In 2015, an estimated 5.9 million cases were diagnosed in men and 3.5 million in women. ${ }^{1}$ An additional 1 mil-

\section{Correspondence author: \\ José Manuel Ramos, \\ Department of Internal Medicine. \\ Hospital General Universitario de Alicante \\ Calle Pintor Baeza 12. Alicante 03010, Spain \\ Tel: +34965933000 \\ Email: jramosrincon@yahoo.es}

lion cases were in children. Nevertheless, tuberculosis is among the five most frequent causes of death in women aged 20 to 59 years ${ }^{2}$, and although pulmonary tuberculosis (PTB) affects a larger proportion of men worldwide, the impact in terms of controlling the disease is greater in women, as it is more likely to be transmitted in the home, especially to children ${ }^{3}$.

It was initially assumed that TB was more common in men because they were more likely to seek care, meaning the burden of TB was underestimated in women. However, prevalence surveys have shown that the TB burden is greater in men even in populations that had not been previously diagnosed ${ }^{4}$. The reasons for differ- 
ences in TB frequency in men and women are poorly understood $^{5}$. Some differences may be related to sex (biological differences) and others related to the socially constructed concept of gender (such as exposure $)^{6-8}$. Sex and gender differences are not only related to the burden of the disease, but also other aspects such as access to diagnostic and treatment services ${ }^{9,10}$. The causes for these differences are wide ranging, and include the direct and indirect costs of healthcare, work-related factors, the distance and transport to healthcare centers, the stigma surrounding the disease and its association with HIV, patients' knowledge of the disease and the experience the of healthcare professionals treating them, adherence to treatment, and satisfaction with the healthcare services ${ }^{9-13}$. Examining the causes and extent of sex and gender inequalities in order to address them in the design and development of healthcare programs could lead to better results ${ }^{6-8}$.

In this study, we aimed to measure differences between the sexes in the epidemiology, clinical characteristics and treatment outcome of TB, including HIV status, in people aged 15 years and older who were treated in accordance with the Tuberculosis and Leprosy Control Programme (TLCP) of Ethiopia ${ }^{14,15}$, in a rural area of the country.

\section{Methods}

\section{Study design, site and period}

We conducted a retrospective cross-sectional study in people with TB aged 15 years and older, collecting data from TB registers and treatment cards. The study period was from 1998 to 2015 (18 years), which we divided this into two nine-year periods, mainly to assess the difference in HIV testing between the two periods.

Gambo General Hospital (GGH) is a 135-bed rural general hospital located in West Arsi, $18 \mathrm{~km}$ from Arsi Negele (main town), $45 \mathrm{~km}$ from Kuyera Hospital (the reference hospital for West Arsi Province), and $250 \mathrm{~km}$ south of Addis Ababa $\left(7^{\circ} 18^{\prime} 22.4^{\prime \prime} \mathrm{N}+38^{\circ} 48^{\prime} 54.7^{\prime \prime} \mathrm{E}\right)$. Due to an inadequate transportation network, the catchment area of GGH is restricted to approximately 95,000 inhabitants. Most of the population live in a rural setting and work in agriculture.

\section{Diagnosis of TB}

The TLCP of Ethiopia is based on the WHO recording and reporting guidelines ${ }^{14,15}$. People with signs and symptoms suggestive of TB are screened so that the diagnosis can be confirmed, and treatment initiated. People with symptoms of pulmonary tuberculosis (PTB) submit three sputum samples: those with at least two positive smears are considered to have smear-positive PTB and those with three negative smears are considered to have smear-negative PTB. The latter group undergo a chest X-ray and are treated with antibiotics during at least 10 days before being retested. Bacteriological methods were direct light smear microscopy (conventional microscopy) to visualize acid-fast bacilli. From September 2013 a light emitting diode (LED) fluorescent microscopy (improves sensitivity) was started. Culture was not performed.

Extra-pulmonary tuberculosis (EPTB) is usually diagnosed clinically 16 . Histopathological examination was performed in some cases by fine needle aspiration or tissue biopsy from accessible mass like peripheral enlarged lymph nodes. The Xpert MTB/RIF assay is considered a great advance over conventional smear for diagnosing tuberculosis (TB) and multidrug resistant (MDR)-TB by simultaneously detecting M. tuberculosis and rifampicin resistant bacilli. Although this assay was not implemented in the study period, the treatment scheme changed, as shown in Annex 1.

People diagnosed with TB at GGH were either admitted to hospital (if they had EPTB or severe PTB), registered in the GGH TB clinic, or referred to a TB clinic near their home. Admitted patients usually stayed in hospital for two to eight weeks. After discharge, some attended the GGH TB clinic and others were referred to TB clinics near their home to complete treatment.

\section{Variables recorded}

All registered patients had a case notification form filled in. The form captured data on age, sex, weight, disease status (new case, relapse, return after default, treatment failure, transfer into GGH, type of TB (smear-positive PTB, smear-negative PTB, EPTB), treatment regimen, treatment outcome (success: cured/completed treatment, transfer out, default, death, failure), HIV status, and other clinical and epidemiological data. We categorized : cured or completed) and unfavorable (loss to follow-up, death, failure and transfer out). "Cured" was defined as patients whose sputum smear or culture was positive at the beginning of the treatment but who was smear- or culture-negative in the last month of treatment and on at least one previous occasion; "treatment completed," patients who completed treatment but who did not have a negative sputum smear or culture result in the last month of treatment and on at least one previous occasion; "treatment failure," patients whose sputum smear or culture was positive at five months or later during treatment, or patients found to harbor 
multidrug-resistant (MDR) strains at any point in time during the treatment, whether they were smear-negative or -positive; "died," patients who had died for any reason during the course of TB treatment; "defaulters," patients on treatment for at least four weeks and whose treatment was interrupted for eight or more consecutive weeks; "transferred out," patients who were transferred to another recording and reporting unit and whose treatment outcomes were unknown. All terms used for type of $\mathrm{TB}$, patient category and treatment outcome were according to the TLCP guidelines ${ }^{14,15}$.

\section{Statistical analysis}

We entered the epidemiological and clinical data in a Microsoft Excel 97 spreadsheet, then performed the analysis using IBM SPSS Statistics V22.0. We used the Chi-squared test and Mann Whitney $\mathrm{U}$ test to compare data where appropriate, interpreting results using crude odds ratios (cOR) and 95\% confidence intervals (95\% $\mathrm{CI}$ ). We fitted a multiple logistic regression model to identify variables associated with TB in women using a stepwise approach. Potential variables for the regression models were chosen based on clinical importance and results of the bivariable analysis; we selected variables showing at least a weak association with TB in women $(p<0.15)$.

The study period was divided into two nine-year periods: 1998 to 2006 and 2007 to 2015, which we compared. Moreover, we compared epidemiological and clinical characteristics and treatment outcomes in HIV+ and HIV- patients.

\section{Ethical approval}

The local Research and Publication Committee of Gambo General Hospital and the Health Unit and Ethical Review Committee of the Ethiopian Catholic Secretary (GH/MSMHF/7350) approved our study. As it was retrospective, we were unable to obtain consent from any of the TB patients. In order to ensure confidentiality, we did not include their names in the data sheet.

\section{Results}

From 1998 to 2015, 3534 people with TB were registered for treatment, 2252 of whom were adults $(\geq 15$ years old): $1172(52 \%)$ men and 1080 (48\%) women (male to female ratio 1.1:1). From 1998 to 2006, 1159 patients were registered: $571(49.3 \%)$ men and 588 (50.7\%), and from 2007 to 2015, 1093: 601 (55.0\%) men and $492(45.0 \%)$ women $(p=0.007)$.

Figure 1 shows the annual rate of TB cases over the study period in all adults and in women and men separately. The overall number of registered TB cases in adults was 161 in 1998, at the beginning of the study. This rate peaked at 186 in 2009 before dropping to 47 cases in 2015. The overall decrease from the beginning to the end of the study period can be attributed to the simultaneous increase in the number of health care facilities offering TB treatment. 


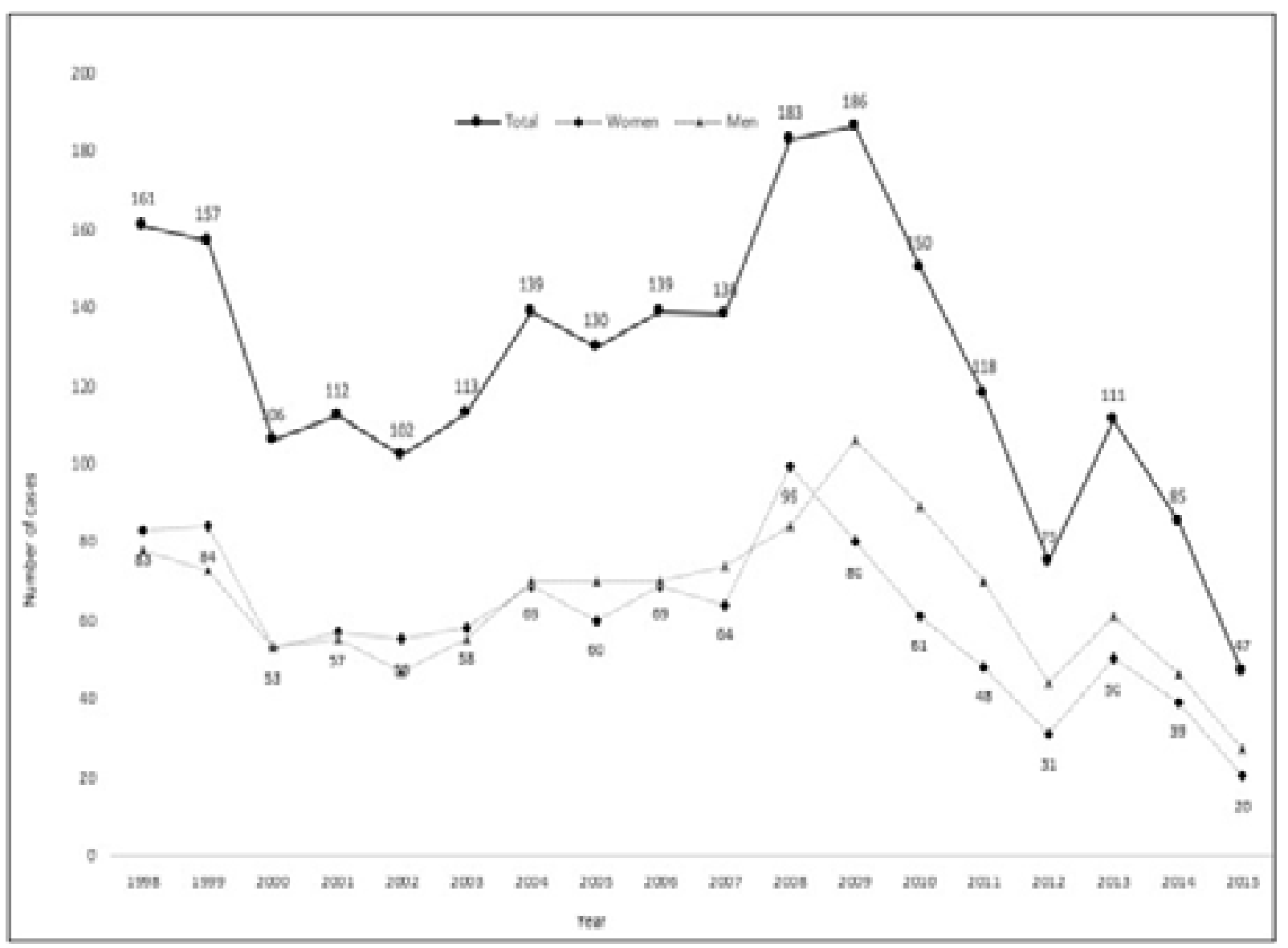

Figure 1. Number of cases of tuberculosis per year in all adults and in women and men separately over the 18-year study period.

Table 1 shows the epidemiological and clinical differences in TB between the sexes. The median age of women was 27.5 years (IQR 20.0, 36.0), similar to that of men (25.0 years, IQR 19.0, 39.0). Median weight in women was $43.0 \mathrm{~kg}$ (IQR: 38.0, 49.0), significantly lower than in men $(50.0 \mathrm{~kg}$, IQR 44.0, 55.0; $\mathrm{p}=0.01)$. More than $93 \%$ of both men and women were newly diagnosed, and between 3.0\% and 3.9\% had been treated previously for TB (relapse or failure). Of all the TB types, $65.9 \%$ and $71.3 \%$ were pulmonary in women and men, respectively. Of these PTB cases, $48.0 \%$ and
$44.6 \%$ were smear positive and $52.0 \%$ and $55.4 \%$ smear negative in women and men, respectively. These data on PTB show no statistically significant differences between the sexes. EPTB was significantly more common in women $(34.1 \%)$ than in men $(28.7 \%)$ with a cOR of $1.28(\mathrm{p}=0.006)$. The most common EPTB subtypes were lymph node TB $(59.5 \%$ in women and $53.6 \%$ in men) followed by osteoarticular TB $(17.1 \%$ in women and $19.0 \%$ in men) and abdominal TB $(15.8 \%$ in women and $14.6 \%$ in men). There were no statistically significant differences in terms of EPTB subtypes between the sexes (table 1). 
Table 1. Epidemiological and clinical characteristics of tuberculosis in all adults and in women and men separately

\begin{tabular}{|c|c|c|c|c|c|}
\hline & $\begin{array}{l}\text { Total* } \\
(\mathrm{N}=2252)\end{array}$ & $\begin{array}{l}\text { Women* } \\
(N=1080)\end{array}$ & $\begin{array}{l}\text { Men* } \\
(N=1172)\end{array}$ & $\begin{array}{l}\text { cOR } \\
(95 \% \mathrm{CI})\end{array}$ & P value \\
\hline Age, median (IQR) & $26.0(20.0,38.0)$ & $27.5(20.0,36.0)$ & $25.0(19.0,39.0)$ & $1.16(0.96,1.27)$ & 0.52 \\
\hline Weight (kg), median & & & & & 0.01 \\
\hline (IQR) & $46.0(40.0-52.0)$ & $43.0(38.0,49.0)$ & $50.0(44.0,55.0)$ & $0.92(0.89,0.96)$ & \\
\hline \multicolumn{6}{|l|}{ TB category } \\
\hline PTB & $1548(68.7)$ & $712(65.9)$ & $836(71.3)$ & 1 & \\
\hline ЕРТВ & $704(31.3)$ & $368(34.1)$ & $336(28.7)$ & $1.28(1.07,1.53)$ & 0.006 \\
\hline \multicolumn{6}{|l|}{ PTB subtype (N=1548) } \\
\hline Smear positive & $715(46.2)$ & $342(48.0)$ & $373(44.6)$ & 1 & \\
\hline Smear negative & $833(53.8)$ & $370(52.0)$ & $463(55.4)$ & $1.47(0.93,1.40)$ & 0.179 \\
\hline \multicolumn{6}{|l|}{ EPTB subtype $(N=704)$} \\
\hline Lymph node TB & $399(56.7)$ & $219(59.5)$ & $180(53.6)$ & $1.27(0.94,1.71)$ & 0.112 \\
\hline Osteoarticular TB & $127(18.0)$ & $63(17.1)$ & $64(19.0)$ & $0.87(0.59,1.29)$ & 0.506 \\
\hline Abdominal TB & $107(15.2)$ & $58(15.8)$ & $49(14.6)$ & $1.09(0.72,1.65)$ & 0.664 \\
\hline CNS TB & $15(0.7)$ & $6(0.6)$ & $9(0.8)$ & $0.97(0.61,1.52)$ & 0.891 \\
\hline Other EРТВ** & $22(3.1)$ & $7(1.9)$ & $15(4.4)$ & - & - \\
\hline Unclassified EPTP & $34(4.8)$ & $13(3.5)$ & $21(6.3)$ & $\mid 0.54(0.27,1.15)$ & 0.93 \\
\hline \multicolumn{6}{|l|}{ Category of TB } \\
\hline New & $2121(94.9)$ & $1025(94.9)$ & $1096(93.5)$ & $1.29(0.90,1.84)$ & 0.159 \\
\hline Transfer in & $38(1.7)$ & $17(1.6)$ & $21(1.8)$ & $0.87(0.46,1.67)$ & 0.698 \\
\hline Failure & $5(0.2)$ & $1(0.1)$ & $4(0.3)$ & $0.27(0.03,2.45)$ & 0.377 \\
\hline Relapse & $73(3.2)$ & $31(2.9)$ & $42(3.6)$ & $0.79(0.49,1.27)$ & 0.340 \\
\hline Other & $12(0.5)$ & $4(0.4)$ & $8(0.7)$ & $0.54(1.62,1.80)$ & 0.541 \\
\hline \multicolumn{6}{|l|}{ HIV status } \\
\hline Known & $1183(52.5)$ & $540(50.0)$ & $643(54.9)$ & 1 & \\
\hline Unknown & $1069(47.5)$ & $540(50.0)$ & $529(45.1)$ & $0.82(0.69,0.97)$ & 0.021 \\
\hline \multicolumn{6}{|l|}{$\begin{array}{l}\text { HIV status results } \\
(\mathrm{N}=\mathbf{1 1 8 3})\end{array}$} \\
\hline Negative & $1120(94.7)$ & $515(95.4)$ & $605(94.1)$ & 1 & \\
\hline Positive & $63(5.3)$ & $25(4.6)$ & $38(5.9)$ & $0.77(0.45,1.29)$ & 0.329 \\
\hline \multicolumn{6}{|l|}{ Hospital admission } \\
\hline No & $1509(67.0)$ & 709 (65.6) & $800(68.3)$ & 1 & \\
\hline Yes & $743(33.0)$ & $371(34.4)$ & $372(31.7)$ & $1.25(0.94,1.34)$ & 0.188 \\
\hline
\end{tabular}

TB: tuberculosis; cOR: crude odds ratio; CI: confidence interval; IQR: interquartile range; PTB: pulmonary tuberculosis; EPTB: extrapulmonary tuberculosis; CNS: central nervous system; HIV: human immunodeficiency virus.

*N (\%) unless otherwise specified

**Other EPTB: Urogenital TB $(n=12)$ Cutaneous TB $(n=4)$, Pericardial TB $(n=4)$, Ocular TB $(n=2)$, Spleen TB $(\mathrm{n}=1)$

During the first half of the study period (1998-2005), only $9.2 \%$ of women and $7.9 \%$ of men were tested for HIV. This rate increased dramatically to $98.8 \%$ and $98.5 \%$ for women and men, respectively, in the second half (2006-2015). Over the whole study period, a slightly lower proportion of women than men were tested for $\operatorname{HIV}(50.0 \%$ vs. $54.9 \%$; $\mathrm{p}=0.021)$, and a slightly lower proportion of women tested positive (4.6\% vs. $5.9 \%)$.
The treatment outcome was similar in women and men, as shown in Table 2. Treatment was successful in 70.3\% of women and $68.9 \%$ of men; $16.9 \%$ of women and $15.8 \%$ of men were transferred out during treatment to a DOTS center near their home, and $6.6 \%$ of women and $7.5 \%$ of men defaulted. The mortality rate was slightly lower in women than in men $(4.7 \%$ vs. $6.4 \%$; $p$ $=0.08)$. 
Table 2. Tuberculosis outcome in all adults and in women and men separately

\begin{tabular}{llllll}
\hline & $\begin{array}{l}\text { Total, N } \\
(\mathbf{N}=\mathbf{2 2 5 2})\end{array}$ & $\begin{array}{l}\text { Women, N (\%) } \\
\mathbf{( N = 1 0 8 0 )}\end{array}$ & $\begin{array}{l}\text { Men, N (\%) } \\
(\mathbf{N = 1 1 7 2 )}\end{array}$ & cOR (95\% CI) & P value \\
\hline Success* & $1566(69.5)$ & $759(70.3)$ & $807(68.9)$ & $1.06(0.89,1.28)$ & \\
Transfer out & $368(16.3)$ & $183(16.9)$ & $185(15.8)$ & $1.08(0.87,1.36)$ & 0.457 \\
Default & $159(7.1)$ & $71(6.6)$ & $88(7.5)$ & $0.86(0.63,1.19)$ & 0.748 \\
Death & $126(5.6)$ & $51(4.7)$ & $75(6.4)$ & $0.72(0.50,1.04)$ & 0.084 \\
Failure & $6(0.3)$ & $5(0.5)$ & $1(0.1)$ & $5.44(0.63,46.69)$ & 0.082 \\
Missing data & $27(1.2)$ & $8(0.7)$ & $16(1.4)$ & -- &.- \\
\hline
\end{tabular}

TB: tuberculosis; cOR: crude odds ratio; CI: confidence interval.

* Treatment completed and patient cured

In an exploratory multivariable analysis testing association with TB in women, we introduced the following variables into the logistic regression model: EPTB, TB adenitis, weight, HIV status and outcome (table 3).
We observed independent associations between TB in women and low weight (adjusted OR aOR: 0.91; 95\% CI $0.90,0.92$ ), less mortality (aOR: $0.54 ; 95 \%$ CI 0.36 , 0.81 ) and lymph node TB (aOR: 1.57; 95\% CI 1.13, 2.19) (table 3).

Table 3. Multivariate analysis of variables associated with tuberculosis in women

\begin{tabular}{lrr} 
& Adjusted OR (95\% CI) & P value \\
\hline Weight $(\mathrm{kg})$, & $0.91(0.90,0.92)$ & $<0.001$ \\
Death & $0.54(0.36,0.81)$ & 0.003 \\
Lymph node TB & $1.57(1.13,2.19)$ & 0.007 \\
EPTB & $1.23(0.93,1.62)$ & 0.125 \\
HIV status & $0.95(0.79,1.14)$ & 0.612 \\
\hline OR: Odds ratio; CI: confidence interval, EPTB: extrapulmonary tuberculosis; HIV: & \\
human immunodeficiency virus &
\end{tabular}

Table 4 and 5 show the epidemiological and clinical differences, along with treatment outcomes in TB from 1998 to 2006 and from 2007 to 2015 . There were more diagnoses of EPTB in 1998-2006 than in 2007-2015 (36.2 vs. 26.1; $\mathrm{p}<0.001$ ), especially for osteoarticular TB (22.7 vs. $11.2 ; \mathrm{p}<0.001)$. Smear-negative PTB was significantly more common in the second period
(31.4\% vs. 59.8\%; $\mathrm{p}=0.001)$. HIV status was unknown in $90.9 \%$ of patients in the first period and $1.4 \%$ in the second $(p<0.001)$. Hospital admissions were fewer in the second period $(37.1 \%$ vs. $28.6 \%$; p < 0.001). Regarding treatment outcomes, transfers out increased $(12.5 \%$ vs. $20.4 \% ; \mathrm{p}<0.001)$ and defaulters decreased (9.3\% vs. $4.7 ; \mathrm{p}<0.001)$. 
Table 4. Epidemiological and clinical characteristics of tuberculosis in 1998 to 2006 period and 2007-2015 period

\begin{tabular}{|c|c|c|c|c|}
\hline & 1998 to $2006(\mathrm{~N}=1159)$ & 2007 to $2015(\mathrm{~N}=1093)$ & $\begin{array}{l}\text { cOR } \\
(95 \% \text { CI) }\end{array}$ & P value \\
\hline \multicolumn{5}{|l|}{ TB category } \\
\hline PTB & $740(63.8)$ & $809(73.9)$ & 1 & \\
\hline ЕРТВ & $419(36.2)$ & $285(26.1)$ & $1.68(1.34,1.92)$ & $<0.001$ \\
\hline \multicolumn{5}{|c|}{ PTB subtype $(\mathrm{N}=1548)$} \\
\hline Smear positive & $508(68.6)$ & $325(40.2)$ & 1 & \\
\hline Smear negative & $232(31.4)$ & $483(59.8)$ & $3.25(2.63,4.01)$ & $<0.001$ \\
\hline \multicolumn{5}{|c|}{ EPTB subtype $(\mathrm{N}=704)$} \\
\hline Lymph node TB & $230(54.9)$ & $169(59.3)$ & $1.11(0.97,1.32)$ & 0.1247 \\
\hline Osteoarticular TB & $95(22.7)$ & $32(11.2)$ & $0.57(0.42,0.78)$ & $<0.001$ \\
\hline Abdominal TB & $63(15.0)$ & $44(15.4)$ & $1.01(0.79,1.30)$ & 0.915 \\
\hline CNS TB & $8(1.9)$ & $7(2.4)$ & $1.12(0.85,1.21)$ & 0.982 \\
\hline Unclassified ЕРТP & $8(1.9)$ & $26(9.1)$ & $1.97(1.68,2.43)$ & $<0.001$ \\
\hline \multicolumn{5}{|l|}{ Category of TB } \\
\hline New & $1088(93.9)$ & $1033(94.5)$ & $1.06(0.87,1.29)$ & 0.519 \\
\hline Transfer in & $28(2.4)$ & $10(0.9)$ & $0.53(0.31,0.91)$ & 0.006 \\
\hline Defaulter & $0(0.0)$ & $5(0.5)$ & - & 0.03 \\
\hline Relapse & $38(3.3)$ & $35(3.2)$ & $0.79(0.49,1.27)$ & 0.918 \\
\hline Other & $4(0.4)$ & $8(0.7)$ & $0.98(0.77,1.22)$ & 0.541 \\
\hline \multicolumn{5}{|l|}{ HIV Status } \\
\hline Known & $105(9.1)$ & 1078 (98.6) & 1 & \\
\hline Unknown & $1054(90.9)$ & $15(1.4)$ & $\begin{array}{l}0.001(0.001, \\
0.002)\end{array}$ & $<0.001$ \\
\hline \multicolumn{5}{|l|}{$\begin{array}{l}\text { HIV Status results } \\
(\mathrm{N}=1183)\end{array}$} \\
\hline Negative & $80(76.2)$ & $1040(96.5)$ & 1 & \\
\hline Positive & $25(23.8)$ & $38(5.9)$ & $0.65(0.53,0.79)$ & $<0.001$ \\
\hline \multicolumn{5}{|l|}{ Hospital admission } \\
\hline No & $729(62.9)$ & $780(71.4)$ & 1 & \\
\hline Yes & $430(37.1)$ & $313(28.6)$ & $0.81(0.74,0.89)$ & $<0.001$ \\
\hline
\end{tabular}

TB: tuberculosis; cOR: crude odds ratio; CI: confidence interval; IQR: interquartile range; PTB: pulmonary tuberculosis; EPTB: extrapulmonary tuberculosis; CNS: central nervous system; HIV: human immunodeficiency virus

$* \mathrm{~N}(\%)$ unless otherwise specified

Table 5. Tuberculosis outcome in all adults and in 1998 to 2006 period and 2007-2015 period

\begin{tabular}{lllll}
\hline & $\mathbf{1 9 9 8}$ to 2006 $(\mathbf{N}=\mathbf{1 1 5 9})$ & $\mathbf{2 0 0 7}$ to 2015 $\mathbf{( N = 1 0 9 3 )}$ & cOR (95\% CI) & P value \\
\hline Success* & $806(69.5)$ & $760(69.5)$ & $1.00(0.83,1.19)$ & 0.996 \\
Transfer out & $145(12.5)$ & $223(20.4)$ & $1.31(1.19,1.44)$ & $<0.001$ \\
Default & $108(9.3)$ & $51(4.7)$ & $0.64(0.51,0.81)$ & $<0.001$ \\
Death & $74(6.4)$ & $52(4.8)$ & $0.84(0.68,1.08)$ & 0.092 \\
Failure & $5(0.4)$ & $1(0.1)$ & $0.34(0.57,2.05)$ & 0.219 \\
Missing data & $21(1.8)$ & $6(0.5)$ & -- & - \\
\hline
\end{tabular}

TB: tuberculosis; cOR: crude odds ratio; CI: confidence interval;

* Treatment completed and patient cured

Table 6 shows the epidemiological and clinical differences as well as the treatment outcomes in the 1183 patients tested for HIV (63 TB/HIV+ and $1120 \mathrm{~TB} /$ HIV-). Median weight in HIV+ individuals was lower than in than HIV- ones (45 vs. 47 kgs.; $\mathrm{p}=0.026$ ). $\mathrm{HIV}+$ patients showed less frequent lymph node TB
$(20 \%$ vs. $57.9 \% ; \mathrm{p}=0.023)$ and successful outcomes $(39.7 \%$ vs. $68.8 \% ;<0.001)$. On the other hand, TB transfer in was more common in HIV+ cases $(4.8 \%$ vs. $1.0 \% ; \mathrm{p}=0.007)$, as was hospital admission $(50.8 \%$ vs. $31.9 \% ; \mathrm{p}=0.002)$, and defaulters and deaths $(17.5 \%$ and $17.5 \%$ vs 4.5 and $4.9 \%, \mathrm{p}<0.001$ and $\mathrm{p}<0.001$, respectively). 
Table 6. Epidemiological and clinical characteristics of tuberculosis in HIV infected and non-infected

\begin{tabular}{|c|c|c|c|c|}
\hline & $\mathrm{TB}^{\prime} / \mathrm{HIV}^{+}(\mathrm{N}=63)$ & $\mathrm{TB} / \mathrm{HIV}^{-}(\mathrm{N}=1120)$ & $\begin{array}{l}\text { cOR } \\
(95 \% \mathrm{CI})\end{array}$ & P value \\
\hline Age, median (IQR) & $30(25-36)$ & $28) 20-40)$ & $1.01(0.99,1.01)$ & 0.722 \\
\hline Weight (kg), median (IQR) & $45(37-51)$ & $47(40-53)$ & $0.97(0.95 \cdot 0.99=$ & 0.026 \\
\hline \multicolumn{5}{|l|}{ TB category } \\
\hline РTB & $53(84.1)$ & $830(74.1)$ & 1 & \\
\hline ЕРТВ & $10(15.9)$ & $290(25.9)$ & $0.58(0.27,1.07)$ & 0.075 \\
\hline \multicolumn{5}{|l|}{ PTB subtype ( $\mathrm{N}=\mathbf{8 8 3})$} \\
\hline Smear positive & $23(43.4)$ & $348(41.9)$ & 1 & \\
\hline Smear negative & $30(56.9)$ & $482(58.1)$ & $1.06(0.60,1.86)$ & 0.834 \\
\hline \multicolumn{5}{|l|}{ EPTB subtype $(\mathrm{N}=704)$} \\
\hline Lymph node TB & $2(20.0)$ & $168(57.9)$ & $0.18(0.03,0.87)$ & 0.023 \\
\hline Osteoarticular TB & $2(20.0)$ & $37(12.8)$ & $1.70(0.35,8.36)$ & 0.503 \\
\hline Abdominal TB & $2(20.0)$ & $47(16.2)$ & $1.29(0.27,6.27)$ & 0.750 \\
\hline CNS TB & $0(0.0)$ & $2(0.7)$ & - & 0.792 \\
\hline Unclassified EPTP & $4(6.3)$ & $36(12.4)$ & $0.20(0.05,0.78)$ & 0.01 \\
\hline \multicolumn{5}{|l|}{ Category of TB } \\
\hline New & $56(88.9)$ & $1059(94.5)$ & $0.46(0.20,1.05)$ & 0.060 \\
\hline Transfer in & $38(4.8)$ & $11(1.0)$ & $5.04(1.37,18.5)$ & 0.007 \\
\hline Defaulter & $0(0.0)$ & $5(0.4)$ & - & 0.595 \\
\hline Relapse & $3(4.8)$ & $35(3.1)$ & $1.55(0.46,5.18)$ & 0.473 \\
\hline Other & $1(1.6)$ & $7(0.6)$ & $2.56(0.31,21.1)$ & 0.365 \\
\hline \multicolumn{5}{|l|}{ Hospital admission } \\
\hline No & $30(50.8)$ & 357 (31.9) & 1 & \\
\hline Yes & $31(49.2)$ & $763(68.1)$ & $2.20(1.35,3.67)$ & 0.002 \\
\hline \multicolumn{5}{|l|}{ Outcome } \\
\hline Success* & $25(39.7)$ & $771(68.8)$ & $0.29(0.18,0.50)$ & $<0.001$ \\
\hline Transfer out & $16(25.4)$ & $238(21.3)$ & $1.29(0.70,2.36)$ & 0.435 \\
\hline Default & $11(17.5)$ & $50(4.5)$ & $4.52(2.23,9.24)$ & $<0.001$ \\
\hline Death & $11(17.5)$ & $55(4.9)$ & $4.09(2.02,8.29)$ & $<0.001$ \\
\hline Failure & $0(0.0)$ & $1(0.1)$ & - & 0.812 \\
\hline
\end{tabular}

TB: tuberculosis; cOR: crude odds ratio; CI: confidence interval; IQR: interquartile range; PTB: pulmonary tuberculosis; EPTB: extrapulmonary tuberculosis; CNS: central nervous system; HIV: human immunodeficiency virus

*N $(\%)$ unless otherwise specified

\section{Discussion}

The most important findings of the study were a slightly lower proportion of TB cases in women than in men but similar treatment outcomes. Women had a slightly lower mortality and more frequent EPTB.

The number of registered TB cases in adults decreased in both women and men during the study period, due to a simultaneous increase in the number of health facilities offering TB treatment in the area ${ }^{17,18}$.

Most studies have found a higher rate of registered TB cases in men $(\mathrm{M}: \mathrm{W} \text { ratio }>1)^{3,19,20}$ though some studies have reported higher rates in women $(\mathrm{M}: \mathrm{W} \text { ratio }<1)^{21,22}$. In our study, the overall M:W ratio of TB incidence was close to 1:1. During the first half of our study period, TB incidence was very similar in both sexes. In the second nine-year period, the proportion of women relative to men decreased for unknown reasons.
As in previous studies, PTB was the predominant TB type ${ }^{1,20,21}$. The ratio of smear-positive to smear-negative PTB was similar in both sexes, in accordance with other series $^{1,20,21}$.

Previous studies have shown a higher preponderance of EPTB in women ${ }^{23,24}$. Similarly, in our study, a significantly higher proportion of women than men had EPTB. We found that lymph node TB was the most common EPTB subtype, as in other studies conducted in women ${ }^{23-27}$. We also found that lymph node TB was slightly more common in women than men. The next most common EPTB subtypes in both sexes were osteoarticular TB and abdominal TB. The higher incidence of bone TB in our study relative to others ${ }^{28}$ might be due to this hospital having a specific TB ward and a policy of admitting patients with spinal TB. After finishing the intensive phase, they are then transferred out to their local health facilities. The incidence of central nervous system TB was lower in our study than in pre- 
vious studies ${ }^{23}$, as our hospital does not have a mycobacterial laboratory, and diagnosing this subtype is thus more difficult.

HIV infection increases susceptibility to $\mathrm{TB}^{1,27,29}$. In our study, few patients were tested for HIV until 2006. During the second nine-year period, however, almost all TB patients were tested, in accordance with the TLCP guidelines ${ }^{29}$. HIV prevalence was around $6 \%$ in both sexes, far lower than the rates reported in previous studies conducted in Ethiopia (between 15\% and $32.2 \%)^{27-31}$. This may be because all the patients included in our study came from rural areas: another study reported lower TB-HIV in people living in rural settings 29. Indeed, the median rate observed in our study was $10 \%$ lower than that reported in a study conducted in an urban health center $18 \mathrm{~km}$ from our hospital ${ }^{32}$. Geographical setting rather than sex therefore appears to be a determinant of HIV prevalence in people with TB.

In part thanks to the TLCP, Ethiopia has successfully reduced the number of premature deaths in association with several diseases, including tuberculosis, over the last 25 years, resulting in a mortality rate of less than $5 \%$ for both sexes $3^{3}$. In our study, the mortality rate of TB patients was lower in women (4.7\% vs $6.4 \%)$, but the difference was not statistically significant. Sex was not associated with favorable or unfavorable outcomes in our study, in accordance with previous studies $^{21,22,24,27,31}$. Age and not sex have been associated with significant differences ${ }^{34}$.

Our study had several limitations. Firstly, this was a retrospective clinical study that used data recorded in the national logbook. This meant we could not include sociological data, and some of the data collected may be imprecise. Secondly, we were unable to collect information about HIV infection, which might have affected the likelihood of a poor outcome. Thirdly, as this was a retrospective study, we could not examine differences in tuberculosis burden and notifications between the sexes 4 , nor could we assess gender-related barriers and delays in accessing tuberculosis diagnostic and treatment services ${ }^{9,10}$. Moreover, GGH is a private hospital, and patients came from other health facilities to be diagnosed. Those who were admitted completed the intensive phase of treatment with us before being transferred out to their local health center. In these cases, therefore, we could not detect failure or death.

Despite these limitations, we can draw several con- clusions from our results. There was a slightly lower proportion of TB cases in women than in men. The main type of TB in both sexes was PTB, but EPTB was more common in women. HIV prevalence in women was less than $5 \%$, slightly lower than in men. Treatment outcome was similar in both sexes, but women had a slightly lower mortality rate. It is important to continue examining the differences in TB between the sexes, and to determine the causes of these differences.

\section{Acknowledgements}

We would like to thank the TB officers at GGH for their assistance in data collection, the laboratory staff for their assistance in the microbiological diagnosis of TB and the nursing staff for their care of the admitted patients. We would also like to thank Meggan Harris for her technical support.

\section{Conflict of interest}

None to declare.

\section{References}

1. Global tuberculosis report 2018. Geneva: World Health Organization; 2018. Licence: CC BY-NC-SA 3.0 IGO; Available from https://www.who.int/tb/publications/global_report/en/ (accessed 25 Mar 19).

2. WHO. Tuberculosis in Women, 2015. Available from http://www. who.int/tb/publications/tb_women_ factsheet_251013.pdf (accessed 30 Sep 17).

3. Shah SK, Dogar OF, Siddiqi K. Tuberculosis in women from Pashtun region: an ecological study in Pakistan. Epidemiol Infect. 2015 Apr;143(5):901-9.

4. Horton KC, MacPherson P, Houben RMGJ, White RG, Corbett EL. Sex Differences in Tuberculosis Burden and Notifications in Low- and Middle-Income Countries: A Systematic Review and Meta-analysis. PLoS Med. 2016;13:1-23 PubMed .

5. Yen YF, Hu HY, Lee YL, Ku PW, Ko MC, Chuang PH, Lai YJ, Chu D. Sexual inequality in incident tuberculosis: a cohort study in Taiwan. BMJ Open. 2018;8(2): PubMed e020142..

6. Hawkes S, Buse K. Gender and global health: Evidence, policy, and inconvenient truths. Lancet; 2013;381(9879):1783 -7. PubMed

7. Vissandjee B, Mourid A, Greenaway CA, Short WE, Proctor JA. Searching for sex- and gender-sensitive tuberculosis research in public health: Finding a needle in a haystack. Int J Womens Health. 2016;8:731-42 PubMed. 8. UN Development Program. UNDP gender equality strategy 2014-2017. 2014. Available from http://www. undp.org/content/dam/undp/library/gender/GenderEqualityStrategy2014-17.pdf

African Health Sciences Vol 20 Issue 2, June, 2020 
9. Krishnan L, Akande T, Shankar A V., McIntire KN, Gounder CR, Gupta A, et al. Gender-Related Barriers and Delays in Accessing Tuberculosis Diagnostic and Treatment Services: A Systematic Review of Qualitative Studies. Tuberc Res Treat. 2014;2014:1-14 PubMed .

10. Asefa A, Teshome W. Total delay in treatment among smear positive pulmonary tuberculosis patients in five primary health centers, southern Ethiopia: a cross sectional study. PLoS One. 2014;9:e102884.

11. Marais BJ, Gupta A, Starke JR, El Sony A. Tuberculosis in women and children. Lancet 2010; 375: 2057-9 PubMed.

12. Bates I, Fenton C, Gruber J, Lalloo D, Lara AM, Squire SB et al. Vulnerability to malaria, tuberculosis, and HIV/AIDS infection and disease. Part II: determinants operating at environmental and institutional level. Lancet Infect Dis 2004; 4: 368-75 PubMed .

13. Holmes CB, Hausler H, Nunn P. A review of sex differences in the epidemiology of tuberculosis. Int $J$ Tuberc Lung Dis 1998; 2: 96-104 PubMed .

14. Federal Ministry of Health (FMOH). Tuberculosis, Leprosy and TB/HIV Prevention and Control Programme Manual. $4^{\text {th }}$ ed. Addis Ababa: MOH; 2008.

15. Federal Ministry of Health (FMOH). Guidelines for Clinical and Programmatic Management of TB, TB/ HIV and Leprosy in Ethiopia. $5^{\text {th }}$ ed. Addis Ababa: MOH; 2013.

16. Ramos JM, Reyes F, Tesfamariam A. Childhood and adult tuberculosis in a rural hospital in Southeast Ethiopia: a ten-year retrospective study. BMC Public Health. 2010;10:215.

17. Marais BJ, Raviglione MC, Donald PR, Harries AD, Kritski AL, Graham SM, et al. Scale-up of services and research priorities for diagnosis, management, and control of tuberculosis: a call to action. Lancet. 2010;375:2179-91

18. Ramos JM, Tesfamariam A, Balcha S, Biru D, Reyes F, Górgolas M. Management and transference of patients diagnosed with tuberculosis in a rural hospital in Southern Ethiopia. Int J Mycobacteriol. 2013;2:79-83.

19. Mekonnen D, Derbie A, Mekonnen H, Zenebe Y. Profile and treatment outcomes of patients with tuberculosis in Northeastern Ethiopia: a cross sectional study. Afr Health Sci. 2016;16:663-70.

20. Tadesse T, Demissie M, Berhane Y, Kebede Y, Abebe M. Incidence of smear-positive tuberculosis in Dabat, northern Ethiopia. Int J Tuberc Lung Dis. 2013;17:630-5. 21. Nigatu T, Abraha M. Epidemiological analysis of tuberculosis in Ethiopia: a ten-year trend analysis. East Afr J Public Health. 2010;7:182-6.

22. Getahun B, Ameni G, Medhin G, Biadgilign S. Treatment outcome of tuberculosis patients under directly observed treatment in Addis Ababa, Ethiopia. Braz J Infect Dis. 2013;17:521-8.

23. Mehraj J, Khan ZY, Saeed DK, Shakoor S, Hasan R. Extrapulmonary tuberculosis among females in South Asia-gap analysis. Int J Mycobacteriol. 2016;5:392-9.

24. Sunnetcioglu A, Sunnetcioglu M, Binici I, Baran AI, Karahocagil MK, Saydan MR. Comparative analysis of pulmonary and extrapulmonary tuberculosis of 411 cases. Ann Clin Microbiol Antimicrob. 2015;14:34.

25. Singh SK, Tiwari KK. Tuberculous lymphadenopathy: Experience from the referral center of Northern India. Niger Med J. 2016;57:134-8.

26. Abebe G, Deribew A, Apers L, Abdissa A, Deribie F, Woldemichael K, et al. Tuberculosis lymphadenitis in Southwest Ethiopia: a community based cross-sectional study. BMC Public Health. 2012;12:504.

27. Alemie GA, Gebreselassie F. Common types of tuberculosis and co-infection with HIV at private health institutions in Ethiopia: a cross sectional study. BMC Public Health. 2014;14:319.

28. Held MFG, Hoppe S, Laubscher M, Mears S, DixPeek S, Zar HJ, et al. Epidemiology of Musculoskeletal Tuberculosis in an Area with High Disease Prevalence. Asian Spine J. 2017;11:405-11.

29. Datiko DG, Yassin MA, Chekol LT, Kabeto LE, Lindtjørn B. The rate of TB-HIV co-infection depends on the prevalence of HIV infection in a community. BMC Public Health 2008; 8: 266.

30. Yassin MA, Takele L, Gebresenbet S, Girma E, Lera $\mathrm{M}$, Lendebo E, et al.. HIV and tuberculosis coinfection in the southern region of Ethiopia: a prospective epidemiological study. Scand J Infect Dis. 2004;36:670-3.

31. Yadeta D, Alemseged F, Biadgilign S. Provider-initiated HIV testing and counseling among tuberculosis patients in a hospital in the Oromia region of Ethiopia. J Infect Public Health. $2013 ; 6: 222-9$.

32. Gebremariam G, Asmamaw G, Hussen M, Hailemariam MZ, Asegu D, Astatkie A, et al. Impact of HIV Status on Treatment Outcome of Tuberculosis Patients Registered at Arsi Negele Health Center, Southern Ethiopia: A Six Year Retrospective Study. PLoS One. 2016;11:e0153239.

33. Misganaw A, Haregu TN, Deribe K, Tessema GA, Deribew A, Melaku YA, et al. National mortality burden due to communicable, non-communicable, and other diseases in Ethiopia, 1990-2015: findings from the Global Burden of Disease Study 2015. Popul Health Metr. 2017 ;15:29.

34. Tesgaye F, Defar A, Beyene T, Shafi O, Klinkenberg E, Howe R. Documentation and treatment outcomes of smear-negative and extra-pulmonary tuberculosis in Ethiopia. Public Health Action. 2014;4(Suppl 3):S25-30. 